\title{
Leaving New Religions
}

\author{
Carole M. Cusack
}

\section{Introduction}

Early studies of joining and leaving new religious movements (henceforth NRMs) exhibited deficiencies found in research on religious conversion in general. These include a tendency to sharply distinguish the pre- and postconversion identity of NRM members, and to view leaving as a simple process. New religions were compared to established religions, and the vocabulary used to describe NRM members differed from that used for Buddhists or Christians. Terms like "recruit" for "convert," and "affiliation" and "disaffiliation" for "conversion" and "apostasy" showed that NRMs were regarded as social movements or "cults" not "religions" (Richardson 1993: 352-354). Disaffiliation, except in cases of alleged "brainwashing" involving deprogrammers (Melton 2004: 232-235), was rarely of interest. From the 1980 s the study of joining and leaving NRMs became more nuanced; it is evident that people leave for a range of reasons. All leavers (like all joiners) are not identical; some retain faith while abandoning membership, while others abandon both.

David Bromley has posited three exit roles for leavers departing organisations: Defector, Whistle-blower, and Apostate (Bromley 1998a: 145). The status of each leaver depends upon the degree of tension with broader culture that the organisation manifests. The majority of leavers do not engage in public airing of grievances, loss of faith, or dispute with religious organisations, but experience departure as an "uncontested leave-taking" (Bromley 1998a: 146). Whistle-blowers and apostates have more difficult exits; they are perceived as disloyal and may be voluble critics of their former religion. Apostates may receive threats and even go into hiding. Because NRMs are, in Bromley's terms, "subversive," exhibiting a high degree of tension with society, apostate roles are prominent for ex-members (Bromley 1998a: 153). There is also doubt about the use of ex-member testimonies. Benjamin D. Zablocki posited "believer," "apostate," and "ethnographer" sources in research on NRMs. He argued "there is very little difference between the reliability (that is, stability across time) of accounts from believers and ex-believers (or apostates)" (cited in Carter 1998: 222). The validity of ex-member accounts is harder to ascertain, given believers 
provide positive accounts while apostates provide negative testimonies. This is not unique to NRMs, but occurs in all religions (see, for example, Larsson 2016). Scholars use member and ex-member sources, adding to them personal observation and external accounts, such as those by journalists.

This chapter describes academic models of conversion and deconversion that have been used to study NRMs, and analyses the concept of "brainwashing" and the use of "deprogramming" (or exit counselling) to forcibly separate individuals from religious groups (Zablocki 1998). This model of leaving NRMs was promoted by the anti-cult movement (ACM), and encouraged ex-members to craft a "captivity" narrative that justified violent intervention (Bromley 1998a: 155). This is followed by a survey of roles adopted by ex-members, and the perspectives they hold regarding the groups they left. The Church of Scientology (henceforth $\mathrm{CoS}$ ) has experienced a high number of departures since 2008 , and is the focus due to a surplus of ex-member memoirs and the emergence of the "Free Zone," a loose network of former Scientologists that still practice L. Ron Hubbard's "tech" outside of CoS structures (Rubin 2011). The Free Zone supports Bromley's idea that "most individuals exiting religious movements labelled subversive are not hostile to the groups with which they were formerly affiliated" (Bromley 1998b: 7). The conclusion reviews scholarship about leaving new religions in the twenty-first century, and suggests areas for further research.

\section{Previous Research and Empirical Material}

The study of NRMs emerged in the 196os, when counter-cultural worldviews and lifeways gained ground as so-called traditional Western religion (especially Christianity) lost explanatory validity and institutional power. These NRMs included: neo-Hindu movements like Transcendental Meditation (TM) and the International Society for Krishna Consciousness (ISKCON), which were founded by Indian gurus, Maharishi Mahesh Yogi (in 1959) and Srila Prabhupada (in 1965) respectively; Western versions of Buddhism emerged as Tibetan and Japanese monks came to the West; Hazrat Inayat Khan's Sufi Order in the West (founded 1914); and other groups like Subud, Scientology, and the Children of God. In the 196os, research on NRMs was mostly conducted by sociologists, and participant observation (usually joining a group temporarily or permanently) was an important technique for gathering information. This reinforced the notion that NRMs did not mandate "true" conversion, but rather "adherence" or the adoption of specific behaviours that mapped out a "conversion career" (Richardson 1980). 
Scholarship on conversion emerged in the early twentieth century. In 1902 William James proposed "tension, deprivation, and subsequent frustration ... as the underlying foundation for conversion" (Gooren 2007:338). The language of conversion and deconversion had Christian origins, as seen in Arthur Darby Nock's Conversion (1933), which focused on religious change in the ancient world (see also Magnusson, Part 1 in this volume). Nock claimed only Christianity required "true" conversion, which he defined as the "reorienting of the soul of an individual, his deliberate turning from indifference or from an earlier form of piety, to another, a turning which implies that a great change is involved, that the old was wrong and the new is right" (Nock 1933: 2). In the 1960s West NRMs were studied variously: for example, as deviant social groups; and as offering insights into the origin of religions. However, they were rarely considered as being of similar importance or legitimacy as, for instance, early Christianity.

Over time, newer models of conversion developed that emphasised stages of interest, participation, and commitment, demonstrating that conversion was a process that is ongoing, rather than a dramatic transformation like that of the apostle Paul on the road to Damascus (Acts 9:3-9). Individuals experience changes throughout life, and joining and leaving religions are thus elements in the development of the self, which is "flexible, amenable to infinite reshaping according to mood, whim, desire and imagination" (Lyon 2002 [2000]: 92). John Lofland and Norman Skonovd's model of conversion identified "motifs" that influenced the self-directed religious quest of seekers (intellectual, experimental, mystical, affectional, and coercive) (Lofland and Skonovd 1981: 375). This differs radically from the "transformation" by God idea based on Christianity.

The NRM milieu offers "seekers" a range of options to experiment with without commitment. Older ideas of evangelism, in which missionaries preached the message to passive populations, sit awkwardly with the active seeker, exploring religions through books, websites, retreats and seminars. As James T. Richardson noted, " $[\mathrm{t}]$ his seeking approach to life is of such importance that some people become members in spite of the absence of some usually expected pressures such as the development of interaction and affective ties between members and prospects" (Richardson 1985: 169). The "seeker" orientation explains leaving as well as joining NRMs; the typical "conversion career" in which a person joins and leaves many religious and spiritual groups in their lifetime is the result of the active, meaning-seeking person taking what they need from each group and moving on when no longer satisfied (Richardson 1980).

Models of leaving new religions proliferated since the 1980 and emphasise a range of factors that may prove decisive. Stuart A. Wright explored familial bonds in NRMs and reconceptualised leaving as equivalent to the breakdown 
of the intimate marital bond in divorce (Wright 1991), also demonstrating that close family ties and parental disapproval are factors in many people leaving NRMs (Wright and Piper 1986: 22). This approach is welcome because it emphasises individual agency, normalises what is often viewed as "deviant" religion preying on weak or psychologically damaged recruits, and permits the leaver mixed feelings about time spent in a NRM. Janet Jacobs used Wright's five-factor model of defection from NRMs to study the power of charismatic leaders and bonds that female members developed with them. These are: "1) the breakdown in member's insulation from the outside world; 2) unregulated development of dyadic relationships within the communal context; 3) perceived lack of success in achieving world transformation; 4) failure to meet affective needs of a primary group; and 5) inconsistencies between the actions of leaders and the ideals they symbolically represent" (Wright cited in Jacobs 1987: 295). The women she interviewed separated from the group first, and only later relinquished the emotional bond they felt with the charismatic leader, even exhibiting "willingness to exonerate the leader from any wrong-doing" (Jacobs 1987: 299). Her interviewees related to their NRM leaders as love objects, and felt emotional pain in losing the connection to them, which reinforces Wright's familial emphasis in explaining leaving NRMs.

\section{3 "Brainwashing" and "Deprogramming” in "Leaving New Religions"}

In the 1960s and 1970s joining NRMs was viewed as deviant behaviour, and an explanatory framework developed that robbed converts of agency and endowed "cults" and their charismatic leaders with powers of "brainwashing" and "coercive persuasion" (Snow and Machalek 1984: 178). These claims emerged during the Korean War (1950-1953), when Chinese soldiers influenced American captives to cooperate, and in rare cases, to defect to communist China. English psychiatrist William Sargant (1907-1988) published Battle for the Mind: A Physiology of Conversion and Brainwashing (1957), which became an important source for the emergent ACM. The application of the "brainwashing" model to NRMS is problematic, in that none were total institutions which effectively imprisoned members, so the prisoner of war analogy was false. Yet it found an audience via popular culture including print and television media (Richardson and Introvigne 2007).

The popular acceptance of "brainwashing" spawned two related phenomena; the "captivity" narrative and the practice of "deprogramming." Bromley described the elements of the former as: the convert presents themselves as innocent of the group's "true" nature and overpowered by "subversive 
techniques;" experiencing brutality and humiliation as a member; escaping from the "cult" and rejecting its teachings; and warning others of the risks they, and society, face from such deviants (Bromley 1998a: 154). Deprogramming, a practice pioneered by Ted Patrick (b. 1930), usually involved kidnapping the NRM member and restraining them for an unspecified time, while engaging in confrontational techniques to get them to relinquish faith. This process was generally instigated by parents, was costly and risky, involved the "abrogation of freedom of religious expression," and was often unsuccessful, with deprogramming subjects often returning to the group (Lewis and Bromley 1987:509).

Richardson identified the "brainwashing" model of conversion to NRMS as a version of the traditional Christian account of the Damascene conversion of Paul, in which "an ostensibly powerful man was totally incapacitated by the actions of the external causal agent [God] focusing on him as an individual" (Richardson 1985:165). The convert is disempowered, and allegedly discards all of their previous beliefs, life experiences and values, with the teachings of the "cult" being adopted entirely after the conversion. Prior to the twentieth century it was assumed that religious conversion in the West was to Christianity, the "true" religion, and thus unproblematic. In the twentieth century the view that religion was undesirable was expressed by Sigmund Freud and others. This gave rise to hypotheses that "deprivation" or other negative factors made some people more susceptible to being converted, a hypothesis that dominated the first half of the twentieth century. In the 1960s and 1970s the secular ACM and the Christian "counter-cult" movement formed; both were involved in promoting the brainwashing and deprogramming model. David A. Snow and Richard Machalek note that the idea that ex-member accounts are hostile, unreliable, and supply evidence supporting the brainwashing hypothesis is because those promoting that hypothesis often rely on "information derived from ex-converts who have been deprogrammed" (Snow and Machalek 1984: 179).

It is now agreed by legal professionals, psychiatrists, religious studies scholars, and psychologists, that "brainwashing" is misleading term, and the phenomenon is invalid and/or non-existent. In 1998 Benjamin D. Zablocki tried to rehabilitate the concept as "exit cost analysis" (Zablocki 1998: 216). He argued that, if restricted to religious groups and relationships between members and charismatic leaders, brainwashing was reframed in terms of exit costs it became a useful concept in understanding how groups retain (rather than attract) members. He drew on rational choice theory, a popular tool in the consumerist reading of religious participation, employed the concept of "religious switching" (Sherkat 1991), and offered a cost-benefit analysis of staying or leaving. He defined brainwashing as "a set of transactions between a charismatically-led collectivity and an isolated agent of the collectivity with 
the goal of transforming the agent into a deployable agent" (Zablocki 1998: 221). Individuals cease to act as agents of themselves, and act as agents of the charismatic authority.

Zablocki's redefinition of brainwashing is interesting; but his research would be more persuasive if the reframed "brainwashing" was subtracted from the argument, as he admits it is rare. Leaving NRMS is a statistically common experience requiring explanation, in which the idea of "exit costs" has value, and can contribute to models that emphasise doubt, searching for alternative roles, and, after a turning point becoming an "ex" rather than a member (Ebaugh 1988). In the twenty-first century the consensus that "brainwashing" and "deprogramming" are pseudo-scientific and with no explanatory value in terms of leaving NRMs has become scholarly orthodoxy. The monograph Agents of Discord: Deprogramming, Pseudo-Science, and the American Anticult Movement (2006) by the late Anson Shupe and Susan E. Darnell chronicled the American attitude to NRMs from the post-War era to the present, charting the rise and fall of the ACM, and proposing a "social economy" model of NRMs in the new millennium (Shupe and Darnell 2006). Yet, brainwashing and deprogramming have survived the onslaught of legal challenges and scientific assessments and have moved sideways into the (related) fields of extremism, terrorism, and counter-terrorism studies (Morris et al. 2010). W. Michael Ashcraft's A Historical Introduction to the Study of New Religious Movements (2018) summarises the history of the field through an examination of the scholars who created it. His focus on identifying the positions, ideological, scientific, and personal, that scholars personally espoused updates the study of NRMs in light of the vital question of situating the researcher in the research (Chenail 2011).

A substantial number of ex-Scientology memoirs have appeared since John Duignan's The Complex: An Insider Exposes the Covert World of Scientology (Duignan and Tallant 2008). These memoirs are not written by rank and file Scientologists, but by those who exited the elite Sea Org (a para-naval group often compared to the Jesuit Order in the Catholic Church). Sea Org members sign "billion year contracts" which commit them permanently to CoS. They work long hours for negligible wages and experience a high level of interference in their personal lives, often separated from spouses, banned from having children, and in the worst case, forced to labour on the Rehabilitation Project Force (Swainson 2017). The authors justified their lives by reference to serving 
charismatic founder L. Ron Hubbard (1911-1986) or his successor David Miscavige (b. 1960). It is difficult to understand why Sea Org members endured such humiliation, violence, and hardship; Zablocki's "exit cost" analysis may appear attractive, as it "is primarily concerned with the paradox of feeling trapped in what is nominally a voluntary association" (Zablocki 1998: 220).

Ex-Scientologists have attracted much attention in the last decade, with memoirs, crusading journalists' exposures of scandals affecting CoS, and films, including Paul Thomas Anderson's feature film starring Joaquin Phoenix and Philip Seymour Hoffman, The Master (2012), Alex Gibney's documentary Going Clear: Scientology and the Prison of Belief (2015), and John Dower's My Scientology Movie (2015), scripted by investigative journalist Louis Theroux. The impact of the Internet is incalculable, from sites hosting confidential CoS materials to online ex-member support groups, like Ex-Scientology Kids, with the tagline "I was born. I grew up. I escaped" (Ex-Scientology Kids 2017). This mass of information about Scientology is remarkable, considering CoS aggressively controlled its public image by using legal means (copyright, libel, and defamation) to prevent apostates and outsiders from publishing negative or critical information about $\operatorname{CoS}$ (Cusack 2012).

As noted, the majority of Scientology defectors are Sea Org members, and the memoirs reveal a life of drudgery, low pay, surveillance, lack of privacy, and violence. This shifts emphasis from the biography and teachings of the charismatic founder of Scientology L. Ron Hubbard, which were the focus of early ex-member books - Jon Atack's A Piece of Blue Sky (1990) and Ronald DeWolf and Bent Corydon's L. Ron Hubbard: Messiah or Madman? (1987) - and journalistic exposés including Russell Miller's Bare-faced Messiah: The True Story of L. Ron Hubbard (1987). Readers of Marc Headley's Blown for Good: Behind the Iron Curtain of Scientology (2009) or Nancy Many's My Billion Year Contract: Memoir of a Former Scientologist (2009) are less concerned with whether L. Ron Hubbard was mentally ill, a liar, or a ruthless monetarist, than with the daily drudgery experienced by the elite Sea Org. Nancy Many converted to Scientology in 1971, but Marc Headley (twenty years her junior) was raised in CoS, educated at the Scientology high school Delphi Academy in Los Angeles, and joined the Sea Org as a teenager. Both worked hundred hour weeks and experienced marital pressure, and both "blew" (left the church). Headley's motorcycle escape involved being "run off the road by the Gold Security suv, attempt(s) to be recovered by at least two other Golden Era staff in vehicles (that I knew of)" and rescue by "the Riverside County Sheriff's department" (Headley 2009: 307). Headley and Many are voluble critics of the church they served selflessly for decades; they have exited both the organisation and the belief system, which they seek to discredit. 
Yet some former members of the CoS continue to practice auditing and to do Training Routines (TRs): in the former an auditor questions a believer using an E-Meter (electropsychometer measuring galvanic skin response) to identify the source of negative memories or engrams; the latter involves working in pairs through various exercises under the supervision of a highly-ranked Scientologist. These ex-members also study the Operating Thetan (OT) levels, collectively known as "The Bridge to Total Freedom," a hierarchical set of esoteric texts that are gradually revealed to Scientologists who have progressed spiritually as members of the Free Zone (Rubin 2011). These ex-Scientologists orient their lives around L. Ron Hubbard's teachings; they express regret at aspects of Scientology that necessitated their departure, chiefly institutional issues and the leadership of David Miscavige (Rubin 2011: 208). Elisabeth Tuxen Rubin's research among Danish ex-Scientologists suggests that many feared leaving because of the CoS practice of "disconnection," shunning by those who remain in the church, even family members. Rubin's informants continued to practice Scientology as individuals, or contacted a group like Ron's Org (started by Captain Bill in 1985) in Switzerland or Germany (Rubin 2011: 209). These exmembers believe while rejecting institutional belonging. Mark "Marty" Rathbun, former Inspector General of the Research Technology Centre, was a key figure in the Free Zone from 2004 when he left Scientology after twenty-seven years. He now identifies as non-religious, and regrets involvement in Theroux's My Scientology Movie, but for more than a decade Rathbun provided Scientology services to Free Zone practitioners, and watching him conduct TRs and direct re-enactments of events at CoS Gold Base near Hemet, California are the highlights of that film (Dower 2015).

The case of Scientology is also important for correlating ex-member testimonies with information contained in critical accounts by investigative journalists, and also with the online publication of confidential church materials. This is a game-changer for scholars, who can now write about controversial topics, and who can test the accuracy of material published by early defectors like Atack and Corydon against originals online. Free Zone practitioners are similarly enabled by the Internet, which connects ex-Scientologists across geographical and other divides. This has implications for the study of leaving NRMs, as while institutions like CoS can expel members, such ex-Scientologists may continue to practice the religion, despite institutional hostility and censure.

In the twenty-first century the study of leaving NRMs has expanded to allow possibilities that were unanticipated in the early studies from the $1960 \mathrm{~s}$ 
and 1970s. It was initially assumed that, as new religions were regarded as less "genuine" than traditional faiths like Christianity, conversion and apostasy were minor phenomena better described as "recruitment" and "disaffiliation" (Richardson 1993). Sociologists of religion initially researched NRMs as social problems and instances of deviance on the part of members. In the 1970s the anti-cult movement and the Christian counter-cult movement promoted the discourse of "brainwashing" and favoured the use of forcible removal of "cult" members by deprogrammers (Zablocki 1998).

In the twenty-first century brainwashing is a discredited concept and deprogramming is seen as a violation of religious freedom and also, on occasion, involving kidnapping which is a criminal offence (Lewis and Bromley 1987). New religions are understood by scholars, and increasingly by the public, as legitimate paths, and the all-pervasive nature of the Internet has increased available information about religions for scholars and interested people alike. The study of leaving new religions has been complicated by the fact that the individualism characteristic of late modern Western culture has resulted in ex-members choosing to exit groups and institutions, but retain their faith or practices; Free Zone Scientology is the clearest example of this (Rubin 2011). The study of leaving NRMs is now part of a religious and spiritual landscape in the late capitalist West that is complicated, contentious, and constantly changing.

\section{References}

Ashcraft, W.M. 2018. A Historical Introduction to the Study of New Religious Movements. London and New York: Routledge.

Bromley, D.G. 1998a. "Linking Social Structure and the Exit Process in Religious Organizations: Defectors, Whistle-Blowers, and Apostates." Journal for the Scientific Study of Religion. 37:1, 145-160.

Bromley, D.G. 1998b. "Sociological Perspectives on Apostasy: An Overview." In D.G. Bromley, ed., The Politics of Religious Apostasy: The Role of Apostates in the Transformation of Religious Movements. Westport: Praeger Publishers, 3-16.

Carter, L.F. 1998. "Carriers of Tales: On Assessing Credibility of Apostate and Other Outsider Accounts of Religious Practices." In D.G. Bromley, ed., The Politics of Religious Apostasy: The Role of Apostates in the Transformation of Religious Movements. Westport: Greenwood, 221-237.

Chenail, R.J. 2011. "Interviewing the Investigator: Strategies for Addressing Instrumentation and Researcher Bias Concerns in Qualitative Research." The Qualitative Report, Vol. 6, No. 1. At: https://nsuworks.nova.edu/cgi/viewcontent.cgi?referer=https:// scholar.google.com.au/scholar?hl $=$ en\&as_sdt $=0 \%{ }_{2} \mathrm{C}_{5} \& \mathrm{q}=$ the + researcher + in + the + research\&btnG $=\&$ httpsredir $=1 \&$ article $=1051 \&$ context $=$ tqr $/$. Accessed $27 / 12 / 2018$. 
Cusack, C.M. 2012. "Media Coverage of Scientology in the United States." In D. Winston, ed., Oxford Handbook of Religion and the American News Media. Oxford and New York: Oxford University Press, 308-318.

Dower, J. 2015. My Scientology Movie. BBC Films.

Duignan, J. (with N. Tallant). 2008. The Complex: An Insider Exposes the Covert World of the Church of Scientology. Dublin: Merlin Publishing.

Ebaugh, H.R.F. 1988. Becoming an Ex: The Process of Role Exit. Chicago: University of Chicago Press.

Ex-Scientology Kids. 2017. Ex-Scientology Kids. At: http://exscientologykids.com. Accessed 11/3/2017.

Gooren, H. 2007. "Reassessing Conventional Approaches to Conversion: Toward a New Synthesis." Journal for the Scientific Study of Religion. 46:3, 337-353.

Headley, M. Blown For Good: Behind the Iron Curtain of Scientology. Burbank: BFG Books.

Jacobs, J. 1987. "Deconversion from Religious Movements: An Analysis of Charismatic Bonding and Spiritual Commitment." Journal for the Scientific Study of Religion. 25:3, 294-308.

Larsson, G. 2016. “'Most Muslims are Like You and I, but "Real” Muslims ...': Ex-Muslims and Anti-Muslim Sentiments." Journal of Muslims in Europe. 5:2, 205-223.

Lewis, J.R., and Bromley, D.G. 1987. "The Cult Withdrawal Syndrome: A Case of Misattribution of Cause?" Journal for the Scientific Study of Religion. 26:4, 508-522.

Lofland, J., and N. Skonovd. 1981. "Conversion Motifs." Journal for the Scientific Study of Religion. 20:1, 373-385.

Lyon, D. 2002 [2000]. Jesus in Disneyland: Religion in Postmodern Times. Cambridge: Polity.

Many, N. 2009. My Billion Year Contract: Memoirs of a Former Scientologist. Northridge: CNM Publishing.

Melton, J.G. 2004. "The Fate of NRMs and Their Detractors in Twenty-First Century America." In P.C. Lucas and T. Robbins, eds, New Religious Movements in the TwentyFirst Century: Legal, Political, and Social Challenges in Global Perspective. London and New York: Routledge, 229-240.

Morris, M., Eberhard, F., Rivers, J., and Watsula, M. 2010. Deradicalization: A Review of the Literature with Comparison to the Literatures on Deganging and Deprogramming . US: Institute for Homeland Security Solutions.

Nock, A.D. 1933. Conversion. Oxford: Oxford University Press.

Richardson, J.T. 1980. “Conversion Careers." Society. 17:3, 47-50.

Richardson, J.T. 1985. "The Active vs. Passive Convert: Paradigm Conflict in Conversion/ Recruitment Research." Journal for the Scientific Study of Religion. 24:2, 119-236.

Richardson, J.T. 1993. "Definitions of Cult: From Sociological-Technical to PopularNegative." Review of Religious Research. 34:4, 348-356. 
Richardson, J.T., and Introvigne, M. 2007. "New Religious Movements, Countermovements, Moral Panics and the Media." In David G. Bromley, ed., Teaching New Religious Movements. Oxford: Oxford University Press, 91-111.

Rubin, E.T. 2011. "Disaffiliation Among Scientologists: A Sociological Study of PostApostasy Behaviour and Attitudes." International Journal for the Study of New Religions. 2:2, 201-224.

Sherkat, D.E. 1991. "Leaving the Faith: Testing Theories of Religious Switching Using Survival Models." Social Science Research. 20:2, 171-187.

Shupe, A., and Darnell, S.E. 20o6. Agents of Discord: Deprogramming, Pseudo-Science, and the American Anticult Movement. New Brunswick, NJ and London: Transaction Publishers.

Snow, D.A., and Machalek, R. 1984. "The Sociology of Conversion." Annual Review of Sociology. 10, 167-190.

Swainson, M. 2017. “The Price of Freedom: Scientology and Neoliberalism.” In J.R. Lewis and K. Hellesøy, eds, Handbook of Scientology. Leiden and Boston: Brill, 200-223.

Wright, S.A. 1991. "Reconceptualising Cult Coercion and Withdrawal: A Comparative Analysis of Divorce and Apostasy." Social Forces. 70:1, 125-145.

Wright, S.A., and Piper, E.S. 1986. "Families and Cults: Familial Factors Related to Youth Leaving or Remaining in Deviant Religious Groups.” Journal of Marriage and the Family. 48:1, 15-25.

Zablocki, B.D. 1998. "Exit Cost Analysis: A New Approach to the Scientific Study of Brainwashing." Nova Religio: The Journal of Alternative Emergent Religions. 1:2, 216-249. 